\title{
МЕТОДОЛОГИЯ СИСТЕМНОГО ПЛАНИРОВАНИЯ ИННОВАЦИОННОЙ ДЕЯТЕЛЬНОСТИ ОРГАНИЗАЦИИ ПРЕДПРИНИМАТЕЛЬСКОГО ТИПА
}

\author{
(c) 2019 Попова Елена Александровна \\ доктор экономических наук, доцент \\ Южно-Уральский государственный университет (НИУ), Россия, Челябинск \\ E-mail: 73519045153@yandex.ru \\ (c) 2019 Базелюк Владимир Васильевич \\ доктор педагогических наук, профессор \\ Южно-Уральский государственный университет (НИУ), Россия, Челябинск \\ E-mail: bazeluk_vladimir@mail.ru \\ (c) 2019 Демин Александр Алексеевич \\ кандидат экономических наук \\ Южно-Уральский государственный университет (НИУ), Россия, Челябинск \\ E-mail:deminaa@susu.ru
}

С позиций методологического анализа дана лидерская оценка системного планирования инновационной деятельности. Организация предпринимательского типа представлена в виде деловых процессов, целевой установкой которых является эффективность и действенность. Особое внимание уделено инновационному характеру внутриорганизационного планирования делового успеха.

Ключевые слова: планирование, системность, инновации, организация, культура, деловой успех.

Поиск и использование инноваций в системе производственно-коммерческой (предпринимательской) деятельности является актуальной проблемой. Развитие новых технических и организационно-технологических решений, совершенствование основных принципов управления применительно к специфике как отечественного, так и зарубежного рынка создают условия для обновления процессов воспроизводства и дают дополнительный импульс для экономического роста. Как правило, российские организации не уделяют должного внимания организационным инновациям.

Любая организационная инновация есть внедрение нового метода управления в деловой практике организации предпринимательского типа (ОПТ), в организации внутрифирменного планирования или внешних связях. Речь, как правило, идет об усовершенствованиях, не затрагивающих выпускаемую ОПТ продукцию и не требующих значительных стартовых инвестиций и времени для их реализации. Это может быть:

- реализация новой или значительно измененной корпоративной стратегии;

- внедрение современных методов управления на основе информационных технологий;
- внедрение новых или значительно измененных организационных структур;

- внедрение современных систем логистики и внутриорганизационного планирования;

- организационное культуростроение;

- внедрение корпоративных систем управления знаниями.

Наиболее распространенными видами организационных инноваций для российских ОПТ являются различные программы по обучению и развитию персонала; применение методов контроля и сертификации; и внедрение информационных технологий. Наименее популярными являются инновации в форме создания исследовательских подразделений, новой организации труда и аутсорсинга.

Нами - в процессе исследования - акцент делается на системном планировании инновационной деятельности, целевой установкой которого является деловой успех. Речь идет о «функции предвидения» (прогнозирования), в основе реализации которой лежат интуитивные методы. Это также осознанный процесс составления смет и бюджетов на кратко- и долгосрочную перспективу. Говоря иначе, системное планирование (СП) является одним из способов «прояснения» внутренних и внешних условий 
достижения делового успеха.

В условиях неопределенности главная задача СП заключается в показе своим потенциальным партнерам, что ОПТ будет в состоянии реально производить продукцию в нужные сроки и с необходимым качеством. А этот показ, в свою очередь, определяется компетентностью руководства и квалификацией персонала, работающего в функциональных подразделениях организации.

Все большую роль в современных условиях играет системное планирование делового успеха. Именно благодаря ему повышается качество принимаемых плановых решений по обеспечению конкурентоспособности в ближайшей и особенно - долгосрочной перспективе.

Данный вид планирования является - по содержанию - не только стратегическим, но и сценарным. Под ним понимается способ анализа внешней среды ОПТ, в которой присутствует множество значимых и влияющих друг на друга тенденций и событий. Благодаря им имеется возможность понять, при каких условиях могут возникнуть благоприятные или неблагоприятные ситуации в осуществляемой - предпринимательской - деятельности.

Можно выделить три этапа такого планирования:

1) анализ внешней среды ОПТ,

2) разработка сценариев развития,

3) разработка стратегии в соответствии с составленными сценариями.

Речь в данном случае идет о системном планировании делового успеха, в котором важно оценить степень взаимовлияния разработанных сценариев и стратегий. Такая оценка осуществляется посредством составления определенной матрицы, в которой основное значение придается вероятности наступления того или иного сценария и его влиянию на деловой успех.

Предпринимательская деятельность (ПД) независимо от ее масштабов и направлений может иметь успех при условии, что лица, которым делегировано право принятия управленческих решений, способны формировать образ желаемого состояния ОПТ. Инновационная деятельность в рамках системного планирования представляет собой четкую последовательность этапов, определяющих цикл подготовки плановых решений, а именно: постановка целей, оценка возможностей, выявление альтернатив, анализ последствий, выбор средств, разработка конкретного плана действий.

Технология СП включает в себя также этапы: выполнения данного плана, контроль результатов, их анализ (с целью оценки делового успеха). Важной задачей последнего этапа является оценка возможностей импровизации в процессе СП. Суть ее заключается в принятии решений на основе сложившейся ситуации и опыта лидера (руководителя) ОПТ (рисунок 1).

Нередко речь при этом идет об импровиза-

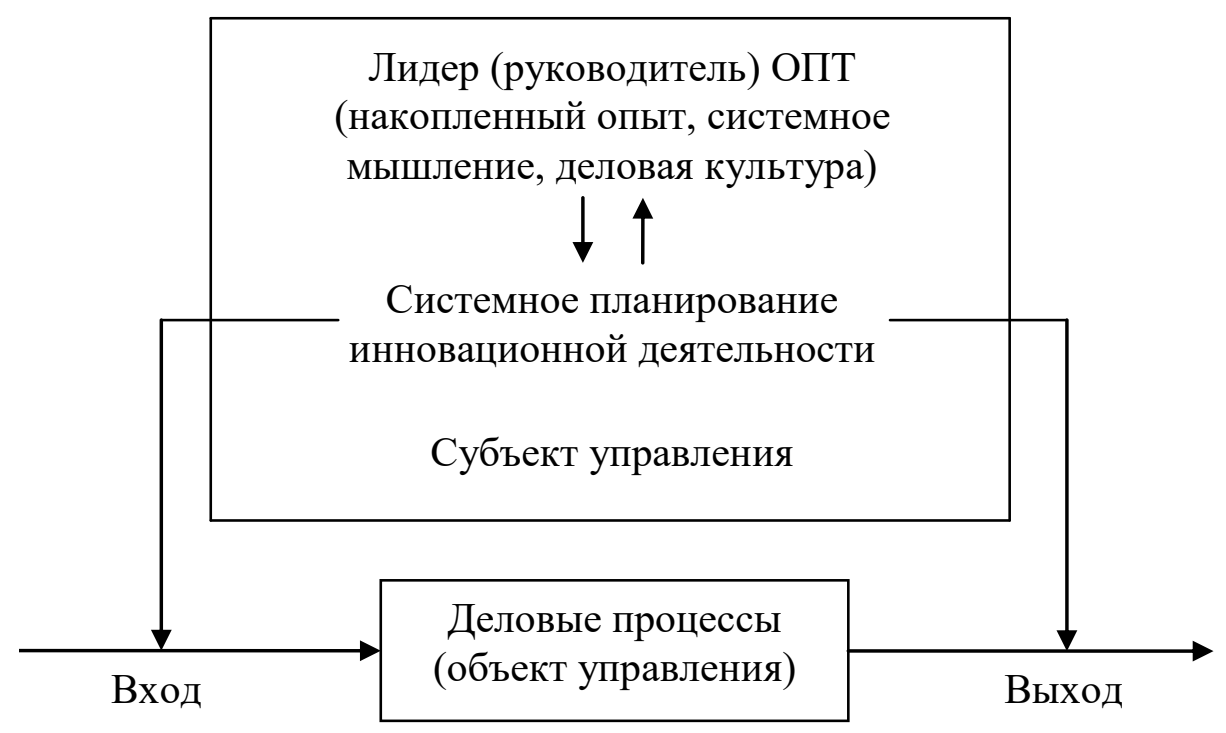

Рисунок 1. Лидерская оценка системного планирования инновационной деятельности ОПТ (организации предпринимательского типа) 
ции, что обусловлено двумя обстоятельствами: 1) несоизмеримостью затрат на планирование с результатами реализации плана; 2) отсутствием объективной, достоверной и достаточной информации, необходимой для разработки плана достижения делового успеха.

Необходимо также учитывать и такие факторы, как: личностные качества; специальные знания; склонность к риску; гибкость; мотивация (гармонизация желаний и интересов с целями решений стратегической направленности); планомерность (собственные возможности и имеющиеся средства, необходимые для подготовки планового решения, их информированность относительно глобальных целей ОПТ); моральнонравственный аспект рассматриваемой деятельности.

Как показывает опыт, деловой успех нередко является следствием не только управленческого, но и предпринимательского таланта, в том числе и в сфере сценарного планирования рассматриваемых систем.

Нами особый акцент в этом плане делается на системном мышлении лидера (руководителя) ОПТ. Данный тип - образ - мышления прежде всего определяется пониманием сути систем (с позиций их методологического анализа). В этой связи интерес представляет рисунок 2 , на котором данная классификация социальноэкономических систем, к числу которых относится и организация предпринимательского типа.
Ключевыми вопросами (с позиций теории и методологии) являются прежде всего: 1) жизнь систем и ее отображение; 2) создание самоорганизующихся систем; 3) строительство систем эффективного управления деловыми процессами. Последний раздел имеет непосредственное отношение к нашему исследованию.

Все системы можно подразделить на естественные и искусственные. В числе последних - духовные и технологические, к которым относятся рассматриваемые нами системы. Они являются принадлежностью ноосферы, то есть области, охваченной разумной человеческой деятельностью.

Методы исследования данных систем нами связываются с управленческой экономикой микроуровня (уровня деловых процессов). Благодаря ей (данной методологии) можно руководствоваться в своих исследованиях эффективного управления деловыми процессами тремя принципиальными особенностями рассматриваемых систем: 1) их динамизмом, изменчивостью во времени; 2) информационностью происходящих процессов; 3) возможностью иерархии уровней управления, придав каждому из них свою степень обобщения изучаемых процессов (тем самым открывается возможность оперировать на каждом уровне соответствующим ему математическим аппаратом со своей аксиоматикой, а значит с адекватной степенью абстрагирования средствами моделирования). Указанные качества, характеризующие управ-

\begin{tabular}{|c|c|c|}
\hline \multicolumn{3}{|c|}{$\begin{array}{c}\text { Методологическая направленность классификации } \\
\text { социально-экономических систем предпринимательского типа }\end{array}$} \\
\hline & 1 & $\downarrow$ \\
\hline $\begin{array}{l}\text { Методологический аспект: } \\
\text { - рождение и гибель } \\
\text { систем } \\
\text { - основные свойства } \\
\text { систем } \\
\text { - описание систем } \\
\text { управления } \\
\text { - классификационные } \\
\text { признаки }\end{array}$ & $\begin{array}{l}\text { Самоорганизующиеся } \\
\quad \text { системы: } \\
\text { - движение систем } \\
\text { управления } \\
\text { - целевые установки } \\
\text { - принципы } \\
\text { управления - } \\
\text { организация } \\
\text { управляемой системы }\end{array}$ & $\begin{array}{l}\text { Строительство систем } \\
\quad \text { управления: } \\
\text { - безопасность систем } \\
\text { - модельное } \\
\text { представление } \\
\text { - оценка эффективности } \\
\text { - подготовка среды к } \\
\text { созданию систем } \\
\text { - опыт создания систем }\end{array}$ \\
\hline
\end{tabular}

Рисунок 2. Методология социально-экономических систем 


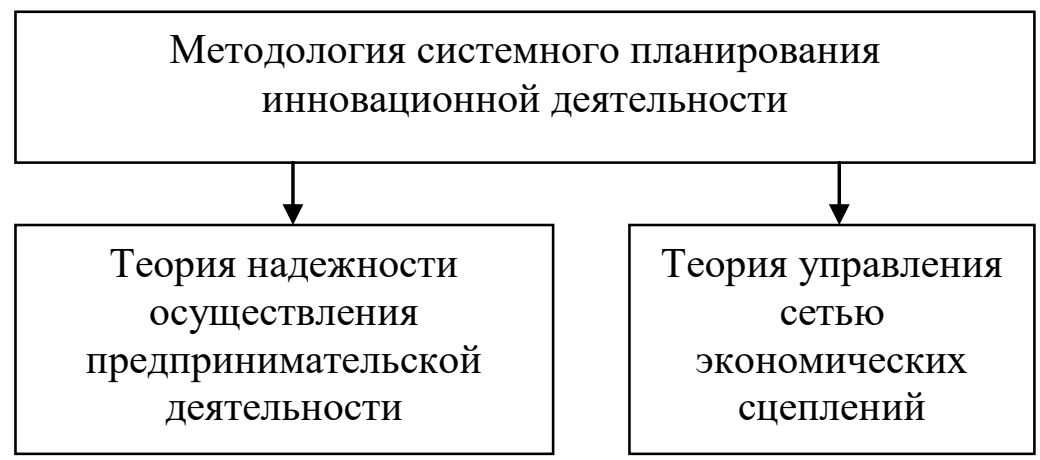

Рисунок 3. Представление методологии системного планирования инновационной деятельности в виде двух теорий

\begin{tabular}{|c|c|}
\hline $\begin{array}{l}\text { 1. Преимущества: } \\
\text { - делает возможной подготовку к } \\
\text { использованию будущих благоприятных } \\
\text { условий; } \\
\text { - проясняет возникающие проблемы; } \\
\text { - стимулирует менеджеров к реализации } \\
\text { своих решений в дальнейшей работе; } \\
\text { - улучшает координацию } \\
\text { внутриорганизационных действий; } \\
\text { - создает предпосылки для повышения } \\
\text { образовательной подготовки менеджеров; } \\
\text { - увеличивает возможности в обеспечении } \\
\text { ОПТ необходимой информацией; } \\
\text { - способствует более рациональному } \\
\text { распределению ресурсов }\end{array}$ & $\begin{array}{l}\text { 2. Недостатки: } \\
\text { - невозможность отразить в } \\
\text { плане все многообразие } \\
\text { жизненных условий, особенно } \\
\text { в сложно организованных } \\
\text { системах; } \\
\text { - стабильность принятого } \\
\text { решения, что может обернуться } \\
\text { убытками при динамичных } \\
\text { обстоятельствах } \\
\text { предпринимательской } \\
\text { деятельности; } \\
\text { - необходимость ресурсов } \\
\text { (времени и средств) для } \\
\text { разработки сценарных планов } \\
\text { инновационного развития }\end{array}$ \\
\hline $\begin{array}{r}\text { Системное п } \\
\text { инновационноі }\end{array}$ & $\begin{array}{l}\text { вание } \\
\text { Іьности }\end{array}$ \\
\hline $\begin{array}{c}\text { 3. Ограничения: } \\
\text { - неопределенность, многомерность и } \\
\text { стохастичность среды } \\
\text { предпринимательской деятельности; } \\
\text { - ограничения по ресурсам; } \\
\text { - проблемы этического свойства в сфере } \\
\text { организационного культуростроения }\end{array}$ & $\begin{array}{l}\text { 4. Искажения: } \\
\text { - авторитарность руководства ОПТ; } \\
\text { - субъективность взглядов } \\
\text { исполнителей; } \\
\text { - неточная и неполная } \\
\text { информация; } \\
\text { - ошибки в экономических } \\
\text { расчетах }\end{array}$ \\
\hline
\end{tabular}

Рисунок 4. Критерии инновационной оценки системного планирования инновационной деятельности (разработаны на основе обобщения имеющегося в этом плане опыта) 
ленческую экономику как теорию, определяют соответствующий уровень абстракции, позволяющий в дальнейшем разработать практические рекомендации по эффективному управлению деловыми процессами. Говоря иначе, речь идет о возможности соединения этих качеств в один, чрезвычайно конструктивный подход, определяющий методологию исследования эволюции самоорганизующихся систем [1].

К такому слиянию трактовок систем эффективного управления деловыми процессами близко подошла теория управления сетью экономических сцеплений, в большей степени вобравшая в себя методологию системного планирования [3]. Схематично данная связь выглядит следующим образом (рисунок 3).
Данная теория еще не распространила свое влияние на широкий класс прикладных задач, решение которых связано с эффективным управлением деловыми процессами. Однако она имеет (что подтверждается нашими исследованиями) прекрасные перспективы развития. Некоторые из них описаны в нашей работе, посвященной методологии управленческой экономики [4].

Нами в процессе исследования выделены критерии инновационной оценки системного планирования инновационной деятельности (рисунок 4). Это его преимущества и недостатки, а также возможные ограничения и возможные искажения. По мере преодоления параметров 2, 3 и 4 степень инновационности, безусловно,

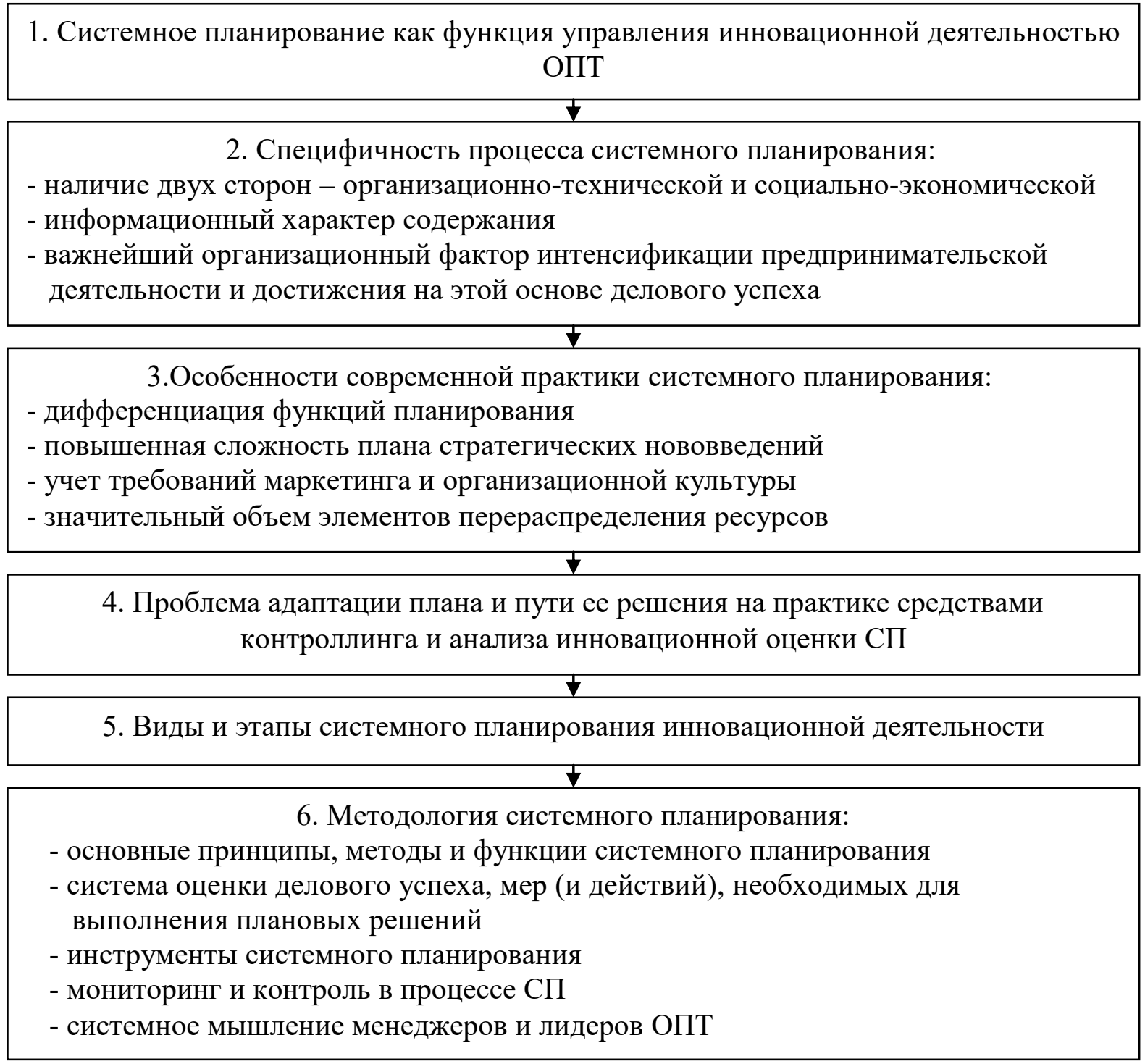

Рисунок 5. Алгоритмическое представление системного планирования инновационной деятельности ОПТ 
возрастают шансы и на деловой успех, особенно если лидеры ОПТ (ее руководители) имеют несколько сценариев развития исходя от ответа на вопрос: «а что, если?».

В качестве обобщения приведем алгоритмическое представление системного планирования инновационной деятельности ОПТ (рисунок 5). Из него следует, что качественно разработанный план данного вида деятельности требует определенной - методологической - основы.

Важным элементом методологии СП являются его принципы: единства, непрерывности, гибкости, точности, участия, научности. Последний принцип, имеющий непосредственное отношение к инновационности действий, подразумевает необходимость использования научного подхода в целях достижения согласованности стратегии делового успеха и конкретных действий ОПТ с реальными параметрами внешней и внутренней маркетинговой среды. Это предполагает: повышение точности прогнозов и планов (использования их различных вариантов - сценариев действий); познание и учет объективных закономерностей, господствующих тенденций развития ОПТ, реальных процессов осуществления деятельности; формирование стратегии делового успеха на основе качественной маркетинговой (и иной) информации.

Само системное планирование имеет собственный информационный цикл, представляющий - по своему содержанию - инновационный процесс (рисунок 6). Его «движущей силой» является или наличие проблемы, или достижение делового успеха. Речь (в том и другом случае) идет о сборе и обработке информации, а также об оценке последствий возможных вариантов (сценариев) плановых решений. После их реализации информация о полученных результатах по каналам обратной связи передается в плановый орган, органически связанный с агентским центром фирмы. Последний на ее основе оценивает происходящее и формулирует новые цели по достижению делового успеха.

Заключая, отметим также, что в рамках любой организации предпринимательского типа складывается своя система СП. Ее создание требует затрат, целесообразность которых обеспечивается инновационной деятельностью агентского центра ОПТ. Критерием эффективности этой деятельности выступает степень использования плана в реальной инновационной деятельности как руководство к действию по достижению делового успеха.

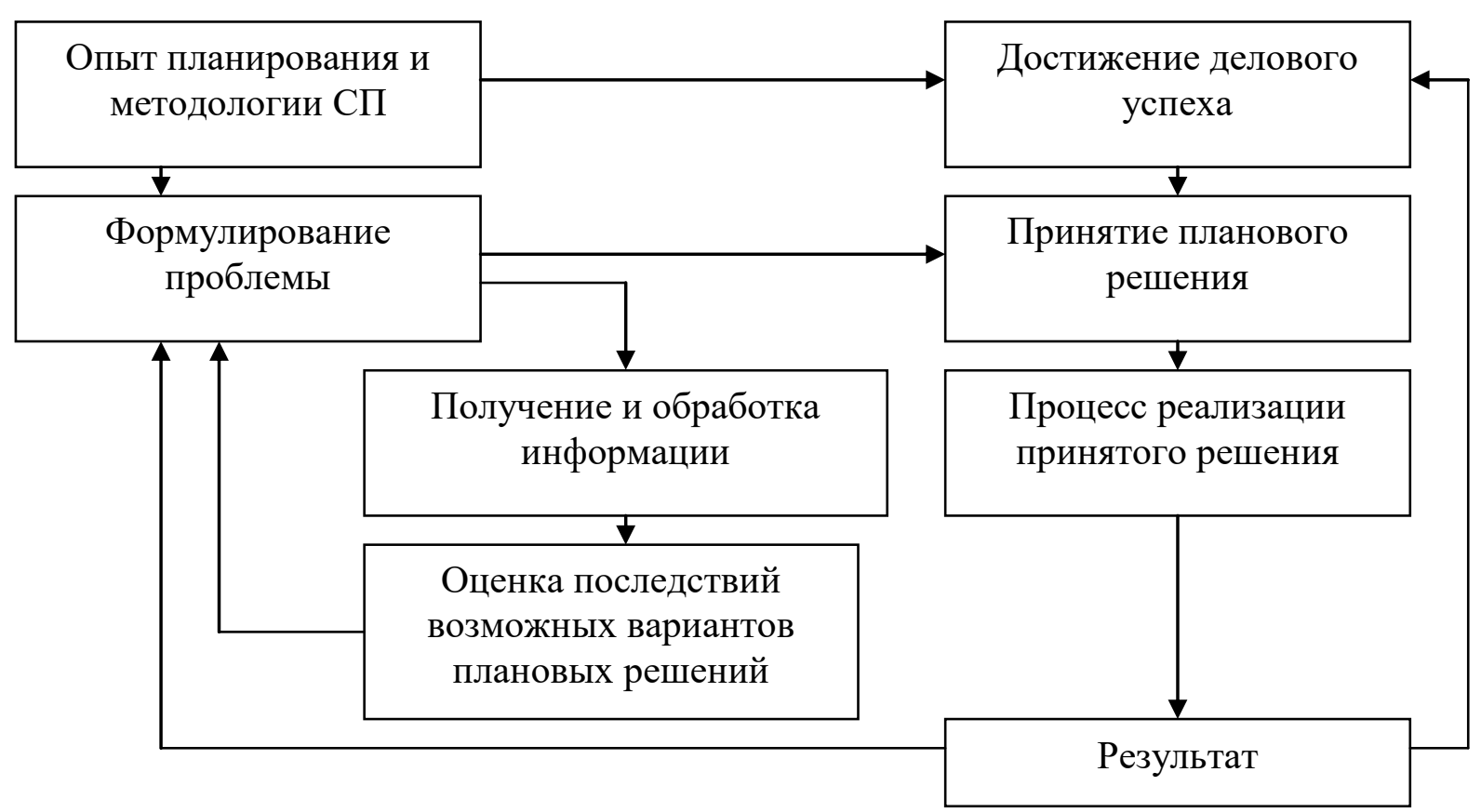

Рисунок 6. Информационный цикл системного планирования как инновационный процесс 


\section{Библиографический список}

1. Алексеева, М. М. Планирование деятельности фирмы / М. М. Алексеева.- М.: ФиС, 2001.-208 с.

2. Инновационный менеджмент: учебное пособие / Под ред. Оголевой Л. Н. - М.: ИНФРА-М, 2001.-238 с.

3. Менщикова, Н.В. Управленческая экономика: инструментарий для принятия управленческих решений / Н.В. Менщикова, Е.А. Попова.- Челябинск: УралГУФК, 2012.- 88 с.

4. Могилевский, В.Д. Методология систем: вербальный подход / В.Д. Могилевский.- М.: Экономика, 1999.$251 \mathrm{c.}$

5. Москалев, А.Н. Обоснование целесообразности реализации организационных инноваций на промышленном предприятии / А.Н. Москалев // Управление, экономический анализ, финансы: сборник научных трудов.- Уфа: УГАТУ, 2012.- С. 70-75.

6. Печаткина, Е.Ю. Теоретические и методологические основы экономического сцепления бизнес-процессов предприятий легкой промышленности / Е.Ю. Печаткина.- Челябинск: ЮУрГУ, 2012.- 212 с.

7. Попов, А.Н. Формирование системы управленческой экономики фирмы / А.Н. Попов, Н.В. Менщикова.Челябинск: УралГУФК, 2010.-114 с.

8. Попов, А. Н. Предпринимательский менеджмент. Инновационная направленность и оценка эффективности / А.Н. Попов, Д.С. Линиченко.- Челябинск: УралГУФК, 2007. - 68 с.

9. Попов, А.Н. Экономика принятия решений / А.Н. Попов, Н.П. Виноградова.- М.: РАЕ, 2017. - 210 с.

10. Уткин, Э.А. Бизнес-план: организация и планирование предпринимательской деятельности / Э.А. Уткин.М.: Экмос, 1997.- 160 с.

11. Финн, Р. Планирование и успех / Р. Финн.- М.: Финпресс, 1999.-118 с.

12. Экономика делового успеха / Н. П. Виноградова, А.А. Попова, А.Н. Попов. - М.: РАЕ, 2017. - 252 с. 